\title{
Structural bionic design for digging shovel of cassava harvester considering soil mechanics
}

\author{
Shihao Liu*, Shaojie Weng, Yulan Liao and Dongyun Zhu \\ College of Mechanical and Electrical Engineering, Hainan University, Haikou, China
}

\begin{abstract}
In order to improve the working performance of cassava harvester, structural bionic design for its digging shovel was conducted. Taking the oriental mole cricket's paws as bionic prototype, a new structural bionic design method for digging shovel was established, which considers the morphology-configuration-function coupling bionic. A comprehensive performance comparison method was proposed, which is used to select the bionic design schemes. The proposed bionic design method was used to improve digging shovel structure of a digging-pulling style cassava harvester, and nine bionic-type digging shovels were obtained with considering the impact of soil mechanics. After conducting mechanical properties comparative analysis for bionic-type digging shovels, the bionic design rules were summed up, and the optimal design scheme of digging shovel was obtained through combining the proposed comprehensive performance comparison method with Analytic Hierarchy Process (AHP). Studies have shown that bionic design method not only can improve the overall mechanical properties of digging shovel, but also can help to improve the harvesting effect of cassava harvester, which provides a new idea for crops harvesting machinery's structural optimization design.
\end{abstract}

Keywords: Cassava harvester, digging shovel, bionic design, structural optimization design

\section{Introduction}

Cassava is a important food crop and new energy material, which is widely cultivated in tropical and subtropical regions [1, 2]. In Hainan, Guangdong, Guangxi and other region of China, cassava is also an important economic crop, and its cultivated area increases year by year. The Chinese national cassava planting area has reached $438000 \mathrm{hm}^{2}$ in 2005 , and 533000 $\mathrm{hm}^{2}$ in 2009. The current cassava planting area of China is about $600,000 \mathrm{hm}^{2}$. According to the estimating of Chinese Ministry of Agriculture, the potential cassava planting area of China will reach 1.5 million $\mathrm{hm}^{2}$ in 2015. Therefore, In order to improve the production efficiency of cassava industry, research and development of high-performance cassava harvester is very necessary. Because digging shovel is an impor-

\footnotetext{
*Corresponding author: Shihao Liu, Doctor, College of Mechanical and Electrical Engineering, Hainan University, Haikou 570228, China. Tel.: +86 898 66267372; Fax: +86 898 66267576; E-mail: liushihao1102@126.com.
}

tant component of the cassava harvester, its digging performance will directly affect the harvesting efficiency of the whole machine. In the current design of cassava harvester's digging shovel, triangular plane spade shovel, convex shovel, concave shovel, and modular shovel are adopted usually. The researchers mainly optimize the structure and size of digging shovels, or use other process measures to improve the mechanical properties of digging shovel. The above studies yet to break through the traditional design ideas, and often result in the mass of digging shovel too large, therefore, it is difficult to meet the high efficient and low energy consumption development trend of modern crop harvesting machinery.

Biological structures have excellent mechanical properties and delicate conformation after millions of years of evolution in the nature, which provides a lot of bionic design prototype and creative improvement methods for mankind to solve the agricultural machinery structural optimization problem [3]. For example, the researchers of Jilin University of China developed 
a bionic scarification component's structural parameter optimization technique through simulating soil animal claw toe's special configuration and its efficient scarification principle. In current, extracting the useful configuration rules of biological structures and applying them to agricultural machinery's structural optimization design has become an important bionic research issue. In recent years, the rising and development of bionics provides a new idea for structural bionic design [4], conducting bionic design for agricultural machinery will be able to achieve more satisfactory design results, which considers the morphology-configuration-function coupling bionic. Therefore, conducting structural bionic design for soilengaging parts to improve their mechanical properties is a very valuable research approach, which has a good reference for multi-objective optimization design of cassava harvester's digging shovel.

Soil animal's claw toe has good mechanical properties to adapt to the ecological environment after millions of years of evolution. Therefore, simulating the conformation characteristics and mechanical properties of soil animal's claw toe is an effective way to obtain the structural bionic design method for cassava harvester's digging shovel. During the cassava harvester's operation process, the shape of digging shovel has great impact on reducing energy consumption and improving harvesting efficiency. In order to solve the problem of soil adhesion and resistance too big, this paper conducted the configuration shape and the main structural parameters' optimization design for digging shovel from the perspective of bionics. The structural bionic design for digging shovel will make it has good structure and mechanical properties, and can help to improve the harvesting performance of the cassava harvester.

\section{Bionic design method for digging shovel}

The development tendency of modern crops harvesting machinery is high efficient and lightweight. In order to improve cassava harvester's harvesting effect during operation in soil, digging shovel should have good being buried performance, removing soil performance and reducing resistance performance. As a kind of soil animal, the oriental mole cricket has high superb soil digging ability and good mechanical properties [5]. Because the oriental mole cricket's forepaws wedge angle has the characteristics of making resistance least, its mechanical properties is so good that artificial shovel digging can't match. Therefore, this paper extracted the outer contour of the oriental mole cricket's forepaws and applied it to design novel bionic structural digging shovel. The digging shovel's bionic design idea is to achieve optimal mechanical properties and digging ability through structural similarity and function similarity.

The similarities between cassava harvester's digging shovel and oriental mole cricket's forepaws include structural similarity, functional similarity and loads similarity. The digging shovel's structural bionic design is based on the mechanical properties advantage of the oriental mole cricket's forepaws. However, the oriental mole cricket's forepaws structure is much more complicated than the traditional digging shovel structure, it is necessary to take the structural manufacturability into account when extracting its mechanical properties. After obtaining bionic-type digging shovel (including shape, dimensions and other parameters) based on oriental mole cricket's forepaws, their parameterized model were built in CAD software. Then, the CAE analysis for the bionic-type digging shovel's mechanical properties was conducted by using finite element software, if the analysis results are not satisfied, a new structural bionic design will be conducted again. The above digging shovel's structural bionic design method is shown in Fig. 1.

In the bionic design process, it usually tends to get a variety of digging shovel structures whose performance indexes are different. In order to select the best bionic design scheme, a comprehensive performance comparison method was proposed in this paper. Supposing $P=\left\{P_{1}, P_{2}, P_{3}, \ldots, P_{n}\right\}^{T}$ is $n$ kinds of bionic-type design schemes of digging shovel, and $U=\left\{U_{1}, U_{2}, \ldots, U_{\mathrm{m}}\right\}$ is $m$ evaluation indexes of each bionic design scheme. According to the fuzzy transformation principle, the evaluation model can be expressed as follows:

$$
\begin{aligned}
C & =\left(C_{1}, C_{2}, \cdots, C_{n}\right)^{T} \\
& =R \bullet W=\left[\begin{array}{cccc}
r_{1,1} & r_{1,2} & \cdots & r_{1, m} \\
r_{2,1} & r_{2,2} & \cdots & r_{2, m} \\
\vdots & \vdots & \ddots & \vdots \\
r_{n, 1} & r_{n, 2} & \cdots & r_{n, m}
\end{array}\right] \bullet\left[\begin{array}{c}
w_{1} \\
w_{2} \\
\vdots \\
w_{m}
\end{array}\right]
\end{aligned}
$$

where, $W$ is the weight vector of performance index; $R$ is a performance evaluation matrix; $C$ is the evaluation result of the $i$-th bionic design scheme, $i=1 \sim n$. 


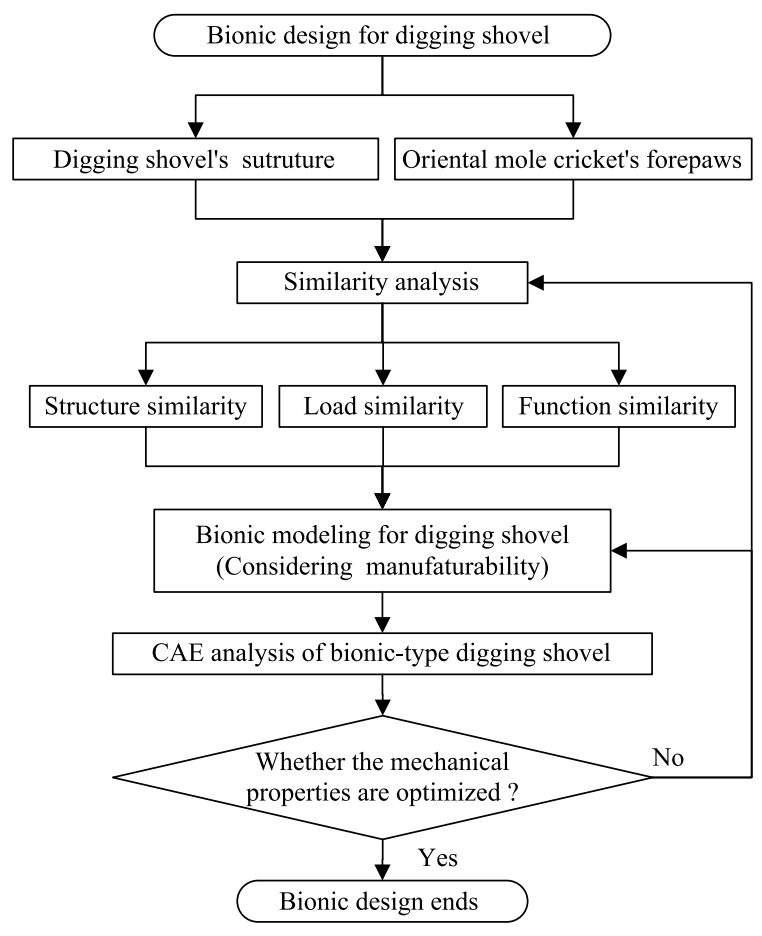

Fig. 1. Bionic design process of digging shovel.

$$
C_{i}=\sum_{j=1}^{m} r_{i, j} w_{j}
$$

Where, $w_{j}$ is the weight coefficient of evaluation $u_{j}$, and $\sum_{j=1}^{m} w_{j}=1, r_{i j}$ is the evaluation value $j$-th performance index of bionic design scheme $P_{i}$ compared with the reference scheme $P 0$, which is a relative value, and is calculated as follows:

$$
r_{i, j}=\operatorname{sign} \frac{u_{i, j}-u_{i, 0}}{u_{i, 0}}
$$

where, sign represents "+" or "-_". When the performance index (such as stiffness) in the bigger the better, it takes a negative sign, otherwise it takes a positive sign positive sign (such as mass, maximum displacement, maximum stress, etc.). Evaluation index $u_{j 0}$ and $u_{j i}$ can be obtained through finite element solution. $u_{j 0}$ means the $j$-th performance index of reference scheme $P 0$, and $u_{j i}$ means the $j$-th performance index of bionic design scheme $P_{i}$. The performance contrast vector $E$ is calculated as follows:

$$
E=\left(E_{1}, E_{2}, \cdots, E_{i} \cdots, E_{n}\right)^{T}
$$

$$
E_{i}=1-C_{i}
$$

where, $E_{i}$ is the performance contrast ratio of bionic design scheme $P_{i}$. Through comparing $E_{i}$, the best structural bionic design scheme can be determined. Note that, the reference scheme $P O$ can be any one of all the bionic design schemes, and its performance contrast ratio is 1 . Because the performance contrast ratio of each scheme is a relative value, the choice of the reference scheme does not affect the optimum seeking result of the digging shovel's structural bionic design schemes.

\section{Structural bionic design of digging shovel}

The study object of this paper is the digging shovel of a kind of digging-pulling style cassava harvester as shown in Fig. 2. The digging shovel's material is gray cast iron HT200, and its material performance parameters are shown in Table 1. From Fig. 2, digging shovel is the main load bearing part, which is fitted with rack and power system. During the cassava harvester's working process, digging shovel bears variable soil resistance. Based on the above analysis, the structure and mechanical properties of the digging shovel has great impact on the cassava harvester's harvesting effect. Therefore, this paper will conduct structural optimization design for digging shovel in according to the idea shown in Fig. 1.

Combining with the digging shovel's structural bionic design method proposed in this paper, the dig-

Table 1

The material parameters of digging shovel

\begin{tabular}{lccc}
\hline Material & Density kg/m & Elastic modulus /GPa & Poisson ratio \\
\hline HT200 & 7300 & 180 & 0.3 \\
\hline
\end{tabular}

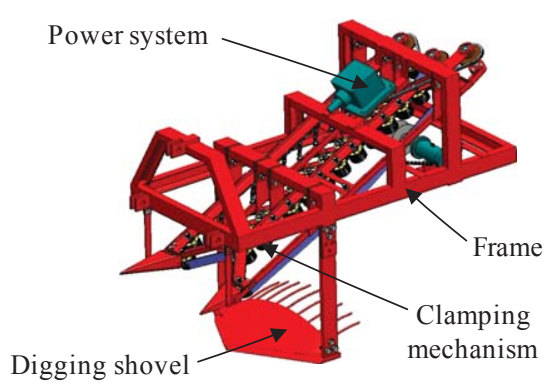

Fig. 2. 3-D model of digging-pulling style cassava harvester. 


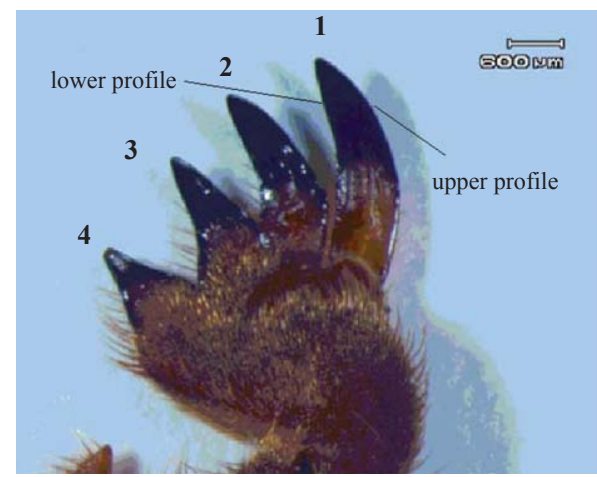

(a) Outer contour

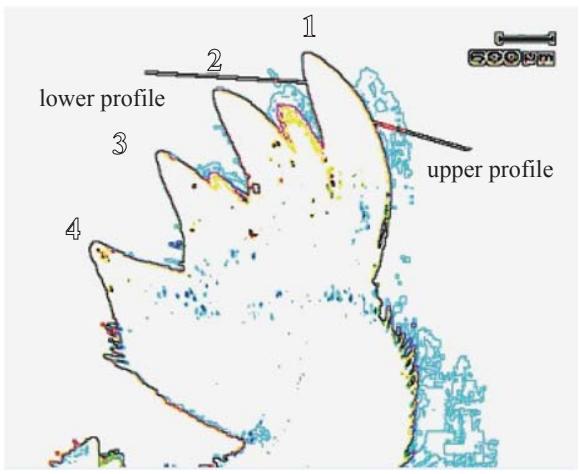

(b) Contour extraction

Fig. 3. Oriental mole cricket's paws.

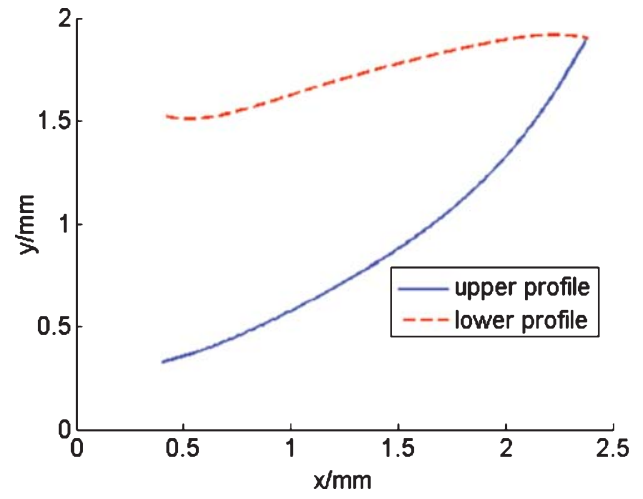

(a) Outer contour's fitting curve

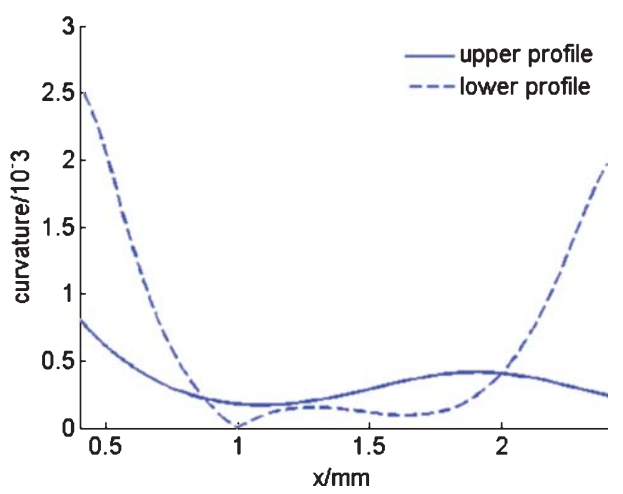

(b) Fitting curve's curvarure

Fig. 4. Outer contour polynomial fitting results.

ging shovels with novel structure were designed trough extracting the outer contour of oriental mole cricket's forepaws, and their 3-D models were built in Pro/E software. The first toe of oriental mole cricket's paws is rather developed, which is shown in Fig. 3(a). Therefore, this paper took the maximum outline curve of oriental mole cricket's paws longitudinal section as the prototype to conduct structural bionic design for cassava harvest's digging shovel.

Importing the image of Fig. 3(a) into CorelDRAW X6 graphic design software, Fig. 3(b) was obtained through extracting its outer contour. Then, changing the bitmap of Fig. 3(b) into vector graphics, and it was saved as dwg format file [5]. Opening the dwg format file in auto $\mathrm{CAD}$, the point set coordinates of upper and lower contour of oriental mole cricket's forepaws were obtained and exported. After conducting polynomial fitting for point set through Matlab software, the appropriate polynomial functions obtained are as follows: the contour curve function is $y_{1}$, the contour curve function is $y_{2}$. The fitting results are shown in Fig. 4.

$$
\begin{aligned}
y_{1}= & 0.1175 x^{4}-0.4986 x^{3}+0.9221 x^{2} \\
& -0.2906 x+0.327 \\
\mathrm{SSE}= & 0.005111, \mathrm{R}-\text { square }=0.9989 \\
y_{2}= & -0.1401 x^{5}+1.021 x^{4}-2.928 x^{3}+4.056 x^{2} \\
& -2.375 x+1.991 \\
\mathrm{SSE}= & 0.002272, \mathrm{R}-\text { square }=0.9972
\end{aligned}
$$

Considering cassava plant growth characteristics, plants' deviation degree and other agronomic factors, the excavation width of the digging shovel was taken as $1000 \mathrm{~mm}$. The fitting equation of forepaw toe's connection projection curve is $f(x)$, and its curve is shown in Fig. 5. 


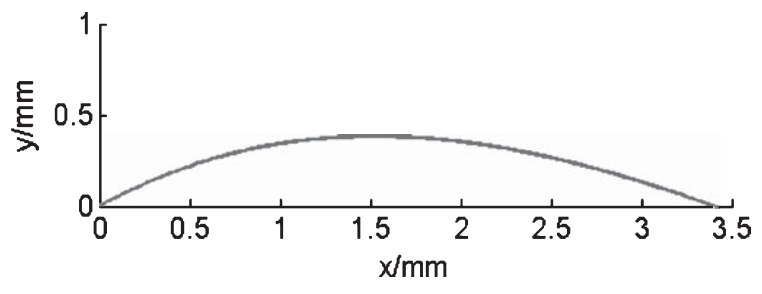

Fig. 5. Toe connection's fitting projection curve.

$$
f(x)=0.01665 x^{3}-0.216 x^{2}+0.5413 x+0.002669
$$

The aforesaid obtained contour curves and forepaws tiptoe connection projection curve's fitting curve were built in Pro/ E software. The forepaws tiptoe connection projection curve was enlarged in according to the width $500 \mathrm{~mm}$, and the outer contour was enlarged in according to a single toe end's width $80 \mathrm{~mm}$. Then, the cross-section graphics of the $1 / 4$ and $3 / 4$ distance of toes were inserted, which are shown in Fig. 6. The

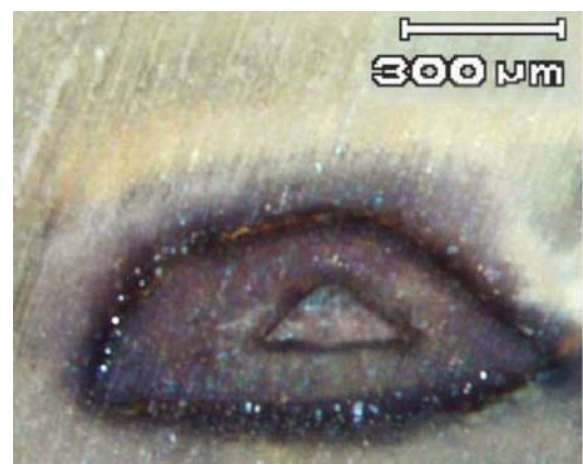

(a) $1 / 4$ distance of toes
3-D models of above cross-section graphics were built by using sketch function and boundary blend command [6].

The cassava's diameter is $40 \mathrm{~mm} \sim 60 \mathrm{~mm}$ in according the field measurement data, therefore, in order to ensure that the cassava will not leak down from the shovel teeth's gap, the minimum spacing between two shovel teeth must be not more than $30 \mathrm{~mm}$. In order to strengthening the digging shovel's strength appropriately, the minimum spacing between two shovel teeth in middle is designed as $8 \mathrm{~mm}$. In according to the design requirements, the width of whole shovel is $1000 \mathrm{~mm}$. The shovel teeth's shape was designed in according to the outer contour polynomial fitting curve. Based on the above methods, the 3-D model of digging shovel simulating oriental mole cricket's forepaws were built in Pre/E software, as is shown in Fig. 7(a).

Taking into account that the oriental mole cricket's paws has hollow structure and the digging shovel is relatively heavy, a digging shovel with hollow shovel

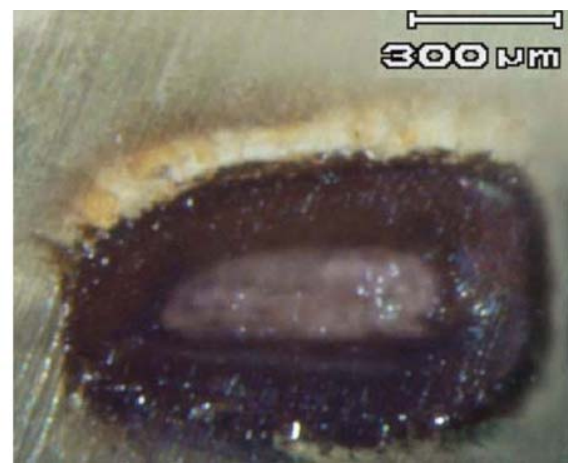

(b) $3 / 4$ distance of toes

Fig. 6. Claw's cross-section.

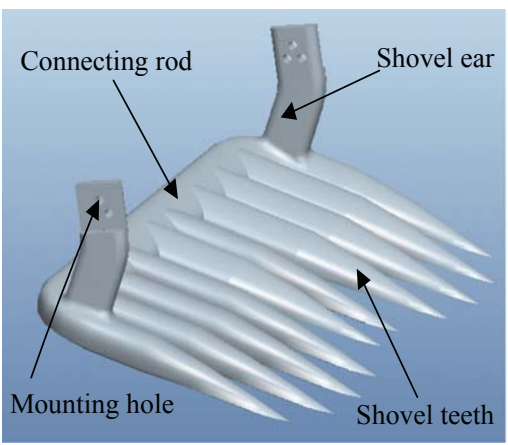

(a) Bionic-type A

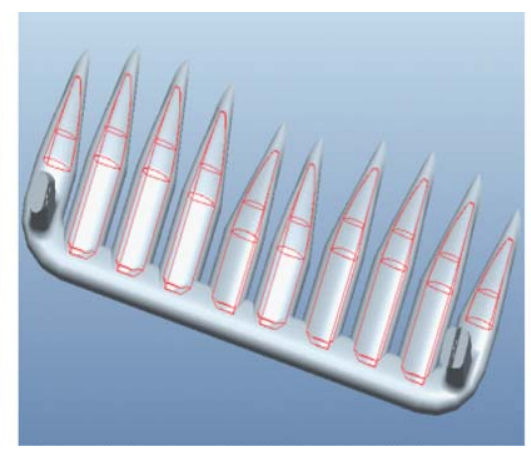

(b) Bionic-type B

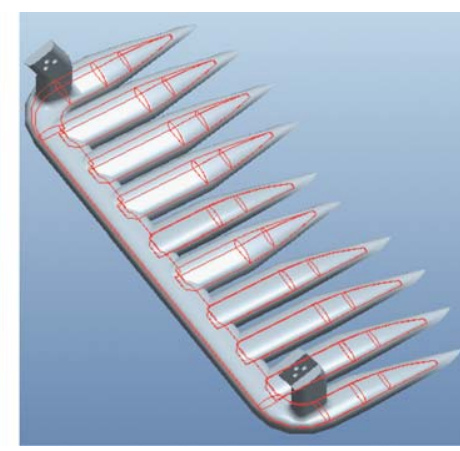

(c) Bionic-type C

Fig. 7. Design three-dimensional model of the shovel. 
Table 2

Bionic-type digging shovels

\begin{tabular}{ll}
\hline Type & Structural characteristics \\
\hline A & Shovel teeth is solid \\
B & Shovel teeth is hollow \\
C & Shovel teeth and connecting rod are hollow \\
\hline
\end{tabular}

teeth was designed (as shown in Fig. 7(b)), and a digging shovel with hollow shovel teeth and connecting rod was designed (as shown in Fig. 7(c)). The structural characteristics of these three kinds of bionic-type digging shovels are shown in Table 2. In the following content, in order to explore the feasibility and correctness of the bionic design method, the structural mechanical properties comparison analysis on bionictype digging shovels were conducted.

\section{Digging shovel's parameters design considering soil mechanics}

The digging shovel's load-bearing in the soil is shown in Fig. 8(a). The soil upper digging shovel and cassava's load-bearing is shown in Fig. 8(b). For convenience, the density of the cassava is defined equivalent to the density of the soil. Under normal circumstances, the soil cutting resistance is so small that can be omitted. Therefore, the digging shovel's traction resistance [7] during moving in the soil is as follows:

$$
W=N_{0} \sin \alpha+\mu N_{0} \cos \alpha+C_{\alpha} A_{0} \cos \alpha
$$

Where: $W$-digging shovel's traction resistance $(\mathrm{N})$;

$N_{0}$ - Shovel surface's normal load,(N);

$\alpha$ - Shovel surface's tilt angle, $\left({ }^{\circ}\right)$;

$\mu$ - Soil-to-metal friction factor;

$C_{\alpha}$ - Soil adhesion coefficient, $\left(\mathrm{N} / \mathrm{cm}^{2}\right)$;

$A_{0}$ - Shovel surface's area, $\left(\mathrm{cm}^{2}\right)$.

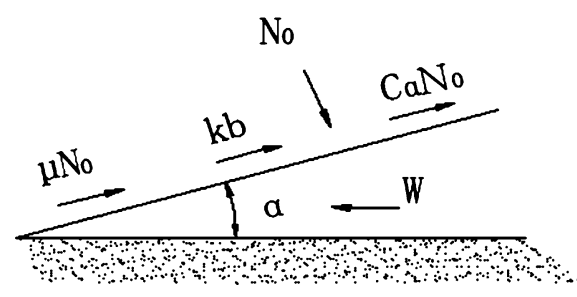

(a) Loads of digging shovel
Without considering the shovel ear, the digging shovel's traction resistance during moving in the soil is as follows [8]:

$$
W_{1}=\frac{G}{Z}+\frac{C A_{1}+B}{Z\left(\sin \beta+\mu^{\prime} \cos \beta\right)}+\frac{C_{\alpha} A_{0}}{Z(\sin \alpha+\mu \cos \alpha)}
$$

where

$W_{1}$ - digging shovel's traction resistance without considering the shovel ear, $(\mathrm{N})$;

$G$ - Gravity of soil and cassava upper digging Shovel, $(\mathrm{N})$;

$\mathrm{Z}$ - Constant;

$\mathrm{C}$ - Soil cohesion coefficient, $\left(\mathrm{N} / \mathrm{cm}^{2}\right)$;

$\mathrm{A}_{1}$ - Soil shear area, $\left(\mathrm{cm}^{2}\right)$;

$\mathrm{B}$ - acceleration force of soil moving along the shovel surface, $(\mathrm{N})$;

$\beta$ - Front failure surface inclination, $\left(^{\circ}\right)$;

$\mu^{\prime}-$ Soil inner friction factor.

When considering the structure of the shovel ear, because the shovel ear will be flooded in soil during digging process, the soil will bear the shear force of shovel ear. Therefore, the digging shovel's traction resistance will generate adding item $[9,10]$.

$$
\Delta \mathrm{W}=\mathrm{sq}_{\mathrm{u}}=S C \tan (45+\varphi)
$$

where

$\Delta W$ - traction resistance's adding item, $(\mathrm{N})$;

$S$ - Effective setsudo area between two shovel ears, $\left(\mathrm{cm}^{2}\right)$;

$q_{u}$ - Unconfined extruding strength, $\left(\mathrm{N} / \mathrm{cm}^{2}\right)$;

$\phi-$ Soil inner friction angle, $\left(^{\circ}\right)$.

Therefore, the digging shovel's traction resistance is as follows:

$$
W=W_{1}+\Delta W
$$

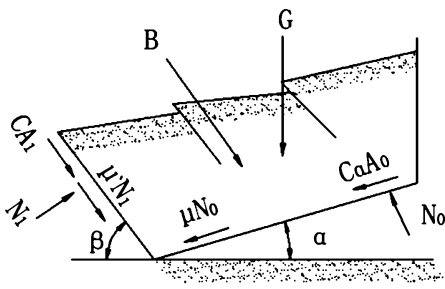

(b) Loads of soil and cassva

Fig. 8. Loads analysis. 
Table 3

Soil's physical characteristics

\begin{tabular}{lcccc}
\hline $\begin{array}{l}\text { Soil Density } \\
\rho /\left(\mathrm{g} / \mathrm{cm}^{3}\right)\end{array}$ & $\begin{array}{c}\text { Soil } \\
\text { cohesion coefficient } \\
\mathrm{C} /\left(\mathrm{N} / \mathrm{cm}^{2}\right)\end{array}$ & $\begin{array}{c}\text { Soil adhesion } \\
\text { coefficient } \\
C_{\alpha} /\left(\mathrm{N} / \mathrm{cm}^{2}\right)\end{array}$ & $\begin{array}{c}\text { Front failure } \\
\text { surface inclination } \\
\beta /\left(^{\circ}\right)\end{array}$ & $\begin{array}{c}\text { Soil inner } \\
\text { friction factor } \\
\mu^{\prime}\end{array}$ \\
\hline 2.6 & 5 & 2.5 & 34 & $\begin{array}{c}\text { Soil-to-metal } \\
\text { friction factor } \\
\mu\end{array}$ \\
\hline
\end{tabular}

Table 4

Shovel surface's structural parameters

\begin{tabular}{|c|c|c|c|c|c|c|}
\hline $\begin{array}{l}\text { Tilt angle } \\
\alpha /\left(^{\circ}\right)\end{array}$ & $\begin{array}{c}\text { Shovel height } \\
h /(\mathrm{mm})\end{array}$ & $\begin{array}{c}\text { Shovel length } \\
L /(\mathrm{mm})\end{array}$ & $\begin{array}{l}\text { Shovel ear's effective } \\
\text { setsudo area } S /\left(\mathrm{mm}^{2}\right)\end{array}$ & $\begin{array}{c}\text { Traction resistance } \\
W /(\mathrm{N})\end{array}$ & $\begin{array}{c}\text { Shovel surface's } \\
\text { normal load } N_{0} /(\mathrm{N})\end{array}$ & $\begin{array}{l}\text { Shovel surface's } \\
\text { pressure } P /(\mathrm{Mpa})\end{array}$ \\
\hline 20 & 200 & 585 & $2 \times 7598.59$ & 38315.67 & 29345.22 & 0.043 \\
\hline 25 & 200 & 473 & $2 \times 7839.63$ & 40421.33 & 32170.90 & 0.062 \\
\hline 30 & 200 & 400 & $2 \times 7703.08$ & 41529.76 & 33248.45 & 0.082 \\
\hline
\end{tabular}

The soil-to-metal friction angle is $30^{\circ} \sim 36^{\circ}$ generally, and this paper takes $34^{\circ}$. Considering that the majority of Hainan cassava is grown in lateritic soil, the clay mining hard to excavate is taken as the research object, and its physical parameters are shown in Table 3.

Because the cassava's growing depth is $20 \mathrm{~cm} \sim$ $40 \mathrm{~cm}$, the excavation depth of the digging shovel is designed as $40 \mathrm{~cm}$. The vertical height between digging shovel's end and shovel tip is designed as $20 \mathrm{~cm}$, so it can make the cassava raise about $20 \mathrm{~cm}$.

In order to avoid the obstruct soil phenomenon and excessive shovel teeth's deformation, the digging shovel's tilt angles is designed as $20^{\circ}, 25^{\circ}$ and $30^{\circ}$, and their structural parameters are shown in Table 4.

\section{Performance comparison and selection for bionic-type digging shovels}

\subsection{Finite element calculating for bionic-type digging shovels}

The 3-D models of bionic-type digging shovels with different tilt angle were built in Pro/E software. After importing the above 3-D models into ANSYS software, their finite element models were built to conduct static structural analysis [11]. The unit type of digging shovel's finite element model is Solid45. Because the digging shovel's shovel ear and the frame are connected by bolts fixed, the fixed constraints were applied on six mounting holes of shovel ear. The digging shovel's traction resistance was obtained from Equations (2-4), and the digging shovel's normal load was obtained from Equation (1).
Table 5

Digging shovel finite element analysis results

\begin{tabular}{lccrcc}
\hline $\begin{array}{l}\text { Tilt } \\
\text { angle }\end{array}$ & $\begin{array}{c}\text { Bionic } \\
\text { type }\end{array}$ & Number & Mass/kg & $\begin{array}{c}\text { Maximum } \\
\text { deformation /mm }\end{array}$ & $\begin{array}{c}\text { Maximum } \\
\text { stress /Mpa }\end{array}$ \\
\hline $20^{\circ}$ & $\mathrm{A}$ & $P_{1}$ & 140.35 & 1.51 & 94.89 \\
& $\mathrm{~B}$ & $P_{2}$ & 106.43 & 1.65 & 93.49 \\
& $\mathrm{C}$ & $P_{3}$ & 93.51 & 1.92 & 95.19 \\
$25^{\circ}$ & $\mathrm{A}$ & $P_{4}$ & 106.77 & 1.09 & 77.01 \\
& $\mathrm{~B}$ & $P_{5}$ & 82.94 & 1.17 & 78.89 \\
& $\mathrm{C}$ & $P_{6}$ & 70.48 & 1.43 & 106.49 \\
$30^{\circ}$ & $\mathrm{A}$ & $P_{7}$ & 84.87 & 0.84 & 73.93 \\
& $\mathrm{~B}$ & $P_{8}$ & 67.32 & 0.93 & 72.11 \\
& $\mathrm{C}$ & $P_{9}$ & 58.87 & 1.07 & 90.77 \\
\hline
\end{tabular}

\subsection{Results and comparative analysis}

The finite element analysis results of mechanical performance parameters of various bionic-type digging shovels are shown in Table 5. Due to limited space, this paper only gives stress and deformation distribution of bionic-type digging shovels with tilt angle $25^{\circ}$, and they are shown in Fig. 9. After conducting comparative analysis on the digging shovels, the main conclusions obtained are as follows.

(1) The bionic-type digging shovels' stress distribution figures show that the stress is mainly in the shovel ear and connecting rod part; the maximum stress occurs at the junction between shovel ear and shovel surface, so the strength problem of this part should be considered when designing and manufacturing the digging shovel. The bionictype digging shovels' deformation distribution figures show that the deformation mainly occurs in front shovel teeth, and the shovel teeth's deformation is greater in middle than in other parts.

(2) Table 3 shows that the maximum stress 106.49 Mpa occurs in digging shovel $P_{4}$, which 


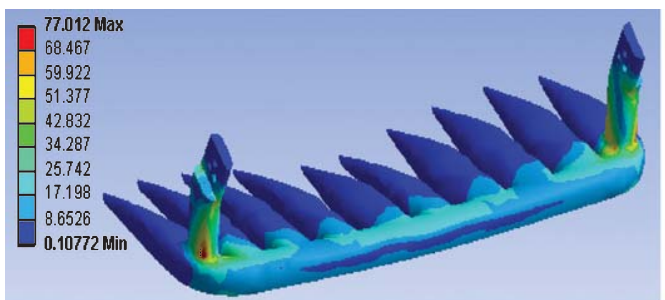

(a) Stress distribution of type A

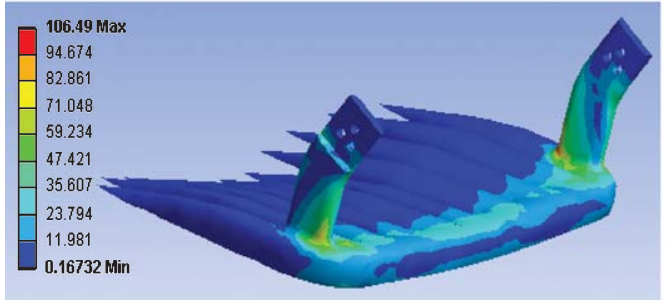

(c) Stress distribution of type $\mathrm{C}$

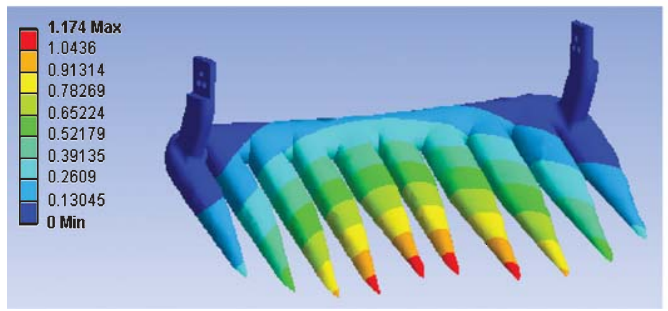

(e) Deformation distribution of type B

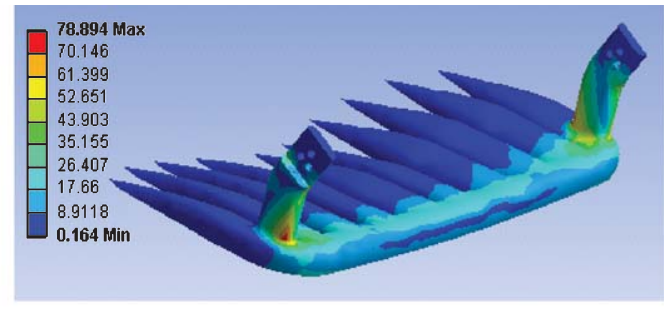

(b) Stress distribution of type B

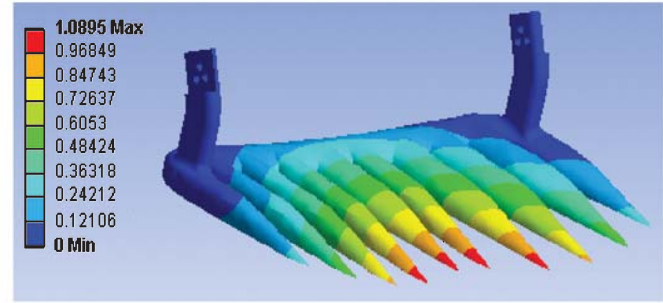

(d) Deformation distribution of type A

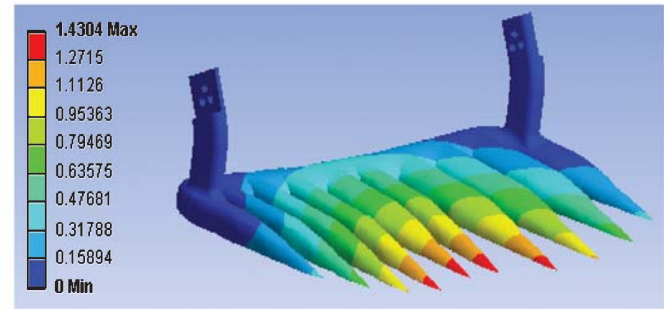

(f) Deformation distribution of type C

Fig. 9. Tilt angle $25^{\circ}$ digging shovel's finite element analysis results.

is far less than the yield strength of the material. Table 3 also shows that the maximum deformation $1.92 \mathrm{~mm}$ occurs in digging shovel $P_{3}$ which is rather small with respect to the length of the digging shovel. Therefore, all the bionic-type digging shovels can meet the design requirements.

(3) As shown in Table 3, with the tilt angle changes from $20^{\circ}$ to $25^{\circ}$, the mass, the deformation and the stress change much more obvious than the tilt angle changes from $25^{\circ}$ to $30^{\circ}$. In order to avoid the obstruct soil phenomenon, the bionic-type digging shovels' tilt angle designed in $25^{\circ} \sim 30^{\circ}$ are more appropriate.

(4) As shown in Table 3, the mass of digging shovel with hollow shovel teeth decreased $24.17 \%$, $22.32 \%$ and $20.71 \%$ comparing to Solid digging shovel, while the change amount of deformation and stress are not very obvious. Although the mass reduction of digging shovel with hollow shovel teeth and connecting rod is not obvious comparing to digging shovel with hollow shovel teeth, but its strain and stress change amount are more obvious. Therefore, digging shovel with hollow shovel teeth is more practical than other digging shovels.

\subsection{Bionic-type digging shovels' selection}

In according to the Table $5, P=\left\{P_{1}, P_{2}, P_{3}, \ldots, P_{9}\right\}$ $T$ can express the nine kinds of bionic-type of digging shovels. In order to select the best digging shovel from the nine bionic-type design schemes, the weight coefficient of each performance index should be determined firstly. This paper uses the Analytic Hierarchy Process (AHP) [12] to determine the weight coefficient. The bionic-type digging shovels' selection process is as follows:

Step 1: Firstly, the evaluation matrix $I=\left(a_{i j}\right)_{m \times m}$ should be built, where $a_{i j}$ is the important scale coefficient that element $i$ relatives to element $j$. In this paper, each element in evaluation matrix $I$ was determined by the cassava harvester designers according to the rules 
Table 6

Judgment rules

\begin{tabular}{ll}
\hline Scale $a_{i j}$ & Meaning \\
\hline 1 & Both elements are equally important \\
3 & The former element is slightly important than the latter \\
5 & $\begin{array}{l}\text { The former element is obviously important than the } \\
\text { latter }\end{array}$ \\
7 & $\begin{array}{l}\text { The former element is strongly important than the latter } \\
9\end{array}$ \\
$\begin{array}{l}\text { The former element is extremely important than the } \\
\text { latter }\end{array}$ \\
Represent the median value of the adjacent judge
\end{tabular}

as shown in Table 6, and the evaluation matrix obtained is shown in (14).

$$
I=\left[\begin{array}{ccc}
1 & 1 & 1 \\
1 & 1 & 2 \\
1 & 1 / 2 & 1
\end{array}\right]
$$

Step 2: In according to $I W=\lambda_{\max } W$, the maximum eigenvalue $\lambda_{\max }$ and the corresponding eigenvectors $W$ can be solved of the evaluation matrix $I$. The weight vector can be obtained by conducting normalized treatment on $W$, which indicates the weight coefficient distribution of each performance index's importance. The weight vector obtained by the consistency test is $W=(0.3275,0.4126,0.2599)^{T}$, namely the weight coefficient of each performance index of digging shovel is shown in Table 7.

Step 3: For the performance index value shown in Table 5, the $P_{1}$ was selected as the reference scheme in this paper. In according to (3), the performance evaluation matrix obtained is as follows:

$$
R=\left[\begin{array}{ccc}
0 & 0 & 0 \\
-0.2417 & 0.0927 & -0.0148 \\
-0.3337 & 0.2715 & 0.0032 \\
-0.2393 & -0.2781 & -0.1884 \\
-0.4090 & -0.2252 & -0.1686 \\
-0.4978 & -0.0529 & 0.1222 \\
-0.3953 & -0.4437 & -0.2209 \\
-0.5203 & -0.3841 & -0.2401 \\
-0.5805 & -0.2914 & -0.0434
\end{array}\right]
$$

In according to Equations (1) and (2), the performance evaluation result voter obtained is as follows:
Table 7

Weight coefficient of each index

\begin{tabular}{lc}
\hline Performance index & Weight coefficient \\
\hline mass & 0.3275 \\
maximum deformation & 0.4126 \\
maximum stress & 0.2599 \\
\hline
\end{tabular}

Table 8

Optimal bionic type digging shovel

\begin{tabular}{lcc}
\hline Bionic type & Tilt angle & Structural characteristics \\
\hline $\mathrm{B}$ & $30^{\circ}$ & shovel teeth is hollow \\
\hline
\end{tabular}

$$
\begin{aligned}
& C=R \bullet W=\left[\begin{array}{ccc}
r_{1,1} & r_{1,2} & r_{1,3} \\
r_{2,1} & r_{2,2} & r_{2,3} \\
\vdots & \vdots & \vdots \\
r_{9,1} & r_{9,2} & r_{9,3}
\end{array}\right] \bullet\left[\begin{array}{c}
w_{1} \\
w_{2} \\
w_{3}
\end{array}\right] \\
&=(0,-0.0448,0.0036,-0.2421,-0.2707, \\
&-0.1531,-0.3699,-0.3913,-0.3216)^{T}
\end{aligned}
$$

Then, $E=(1,1.0448,0.9964,1.2421,1.2707$, $1.1531,1.3699,1.3913,1.3216)^{T}$, so the overall performance contrast order of the bionic-type digging shovels is $P_{8}>P_{7}>P_{9}>P_{5}>P_{4}>P_{6}>P_{2}>P_{1}>P_{3}$, which means the scheme $P_{8}$ is the optimal one. The selection result is consistent with the above analysis conclusions in section 4.2. The structure and parameters of scheme $P_{8}$ are shown in Table 8 .

\subsection{Result analysis for digging shovel's bionic design}

The bionic-type digging shove manufactured according to scheme $P_{8}$ is assembled very well with other components in 4UMS-1 type cassava harvester prototype, which reduces the whole machine's mass and manufacturing costs. In addition, as shown in Fig. 10, the field test results show that the digging shovel's tubers uprooted process runs smoothly, and the harvesting effect has been improved. In field test, the cassava harvester was manufactured by Hainan Jinlu Agricultural Machinery Development Co., Ltd of China, whose power capacity is $17.6 \mathrm{kw}$, velocity is $4 \mathrm{~km} / \mathrm{h}$, test time is $4.5 \mathrm{~h}$. Therefore, bionictype digging shovel designed in this paper has good mechanical properties, which proved that the digging shovel's bionic design method proposed has high practicability. 


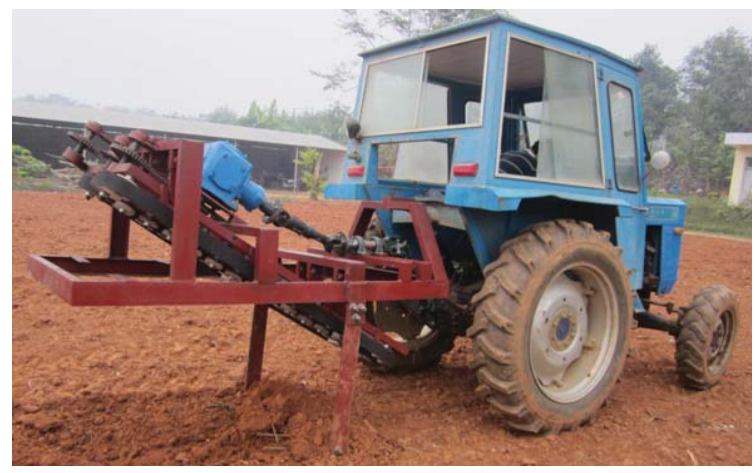

Fig. 10. Cassava harvester prototype's field test.

\section{Conclusions and future works}

(1) The oriental mole cricket's forepaws were used to design nine bionic-type digging shovels with considering soil mechanics, and the optimal bionic-type design scheme was obtained through combining AHP with comprehensive performance comparison method proposed in this paper. In according to the similarity principle, the bionic design method of simulating the soil animal's claws structure was proposed in this paper, which breaks the traditional empirical design methods, and provides a new idea for cassava harvester's structural optimization design.

(2) Through conducting comparative analysis, the mechanical properties rules of bionic-type digging shovels were summed up, which are as follows: the bionic-type digging shovel's stress is mainly in the part of shovel ear and connecting rod, the maximum stress occurs at the junction between shovel ear and shovel plane, the deformation occurs in the front of shovel teeth, and the shovel teeth's deformation is greater in middle than in other parts.

(3) The novelty of this paper is that a structural bionic design method and a comprehensive performance comparison method for cassava harvester's digging shovel are proposed in this paper. The structural bionic design method can be used to obtain a lot of digging shovel design schemes with good mechanical properties. The comprehensive performance comparison method can be used to select the optimal design scheme from a lot of bionic-type digging shovels.

(4) This paper had carried out structural bionic design for cassava harvester's digging shovel, so the dig- ging shovel achieved lightweight structure and its mechanical properties was improved. Because the structure of bionic-type digging shovel is more complex than traditional structure, in order to improve the engineering practicability of the digging shovel's bionic design method, the technology how to simplify the manufacturing process of bionic-type digging shovel will be the following research focus.

\section{Acknowledgments}

We are grateful for the financial support by National Natural Science Foundation of China (Project number: 51365011).

\section{References}

[1] W. Yang, J. Yang, X.T. Zheng, Q.Y. Wang, F.Y. Jia and J.Q Zhao, Experiment on mechanical properties of cassava, Transactions of the Chinese Society of Agricultural Engineering 27(14) (2011), 50-54.

[2] Y.L. Liao, Y.P. Sun, S.H. Liu, D.P. Chen and G.P. Wang, Development and prototype trial of digging-pulling style cassava harvester, Transactions of the Chinese Society of Agricultural Engineering 28(26) (2012), 29-35.

[3] Y. Zhang, H. Huang and L.Q. Ren, Experiment and drag reduction mechanism of bionic excavator tooth during soil cutting, Transactions of the Chinese Society for Agricultural Machinery 44(1) (2013), 258-261.

[4] L.Q. Ren and Y.H. Liang, Coupling bionics, Science press, Beijing, 2012, pp. 19-25.

[5] J. Tong, H. Gao and J.Y. Sun, Microstructure and nanoindentation properties of foreleg's tarsal claw of the oriental mole cricket (gryllotalpa orientalis burmeister), Transactions of the Chinese Society for Agricultural Machinery 40(5) (2009), 190-193.

[6] H. Gao, Characteristic, function, mechanics and bionic analysis of oriental mole cricket (Gryllotalpa orientalis burmeister), Ph.D Dissertation, Jilin University, 2009.

[7] L.Q. Ren, X.B. Xu, B.C. Chen, B.L. Zhang, L.H. Ge and G.P. Jin, Preliminary analysis of typical forms of soil animals claw toe, Transactions of the Chinese Society for Agricultural Machinery 40(5) (2009), 190-193.

[8] D.P. Chen, The Study of the Digging-pulling Cassava Harvester Digging Components, Master Dissertation, Hainan University, 2012

[9] H. Chen, W.W. Wu, X.T. Lin and H.W. Li, Effect of wheel traffic on working resistance of agricultural machinery in field operation, Transactions of the Chinese Society for Agricultural Machinery 41(2) (2010), 52-57.

[10] Y.L. Li, B. Liu, T. Cui and D.X. Zhang, Design and field experiment on 1sz-460 lever-type subsoiler, Transactions of the Chinese Society for Agricultural Machinery 40(Z1) (2009), $37-40$. 
[11] J.X. Jia, D.X. Zhang and Y.Y. Sang, Computer aided analysis and simulation experiment of potato digging blade, Transactions of the Chinese Society of Agricultural Engineering 22(8) (2006), 106-110.
[12] A. Serhat and K. Cengiz, Multiattribute supplier selection using fuzzy analytic hierarchy process, International Journal of Computational Intelligence Systems 3(5) (2010), 553565 . 

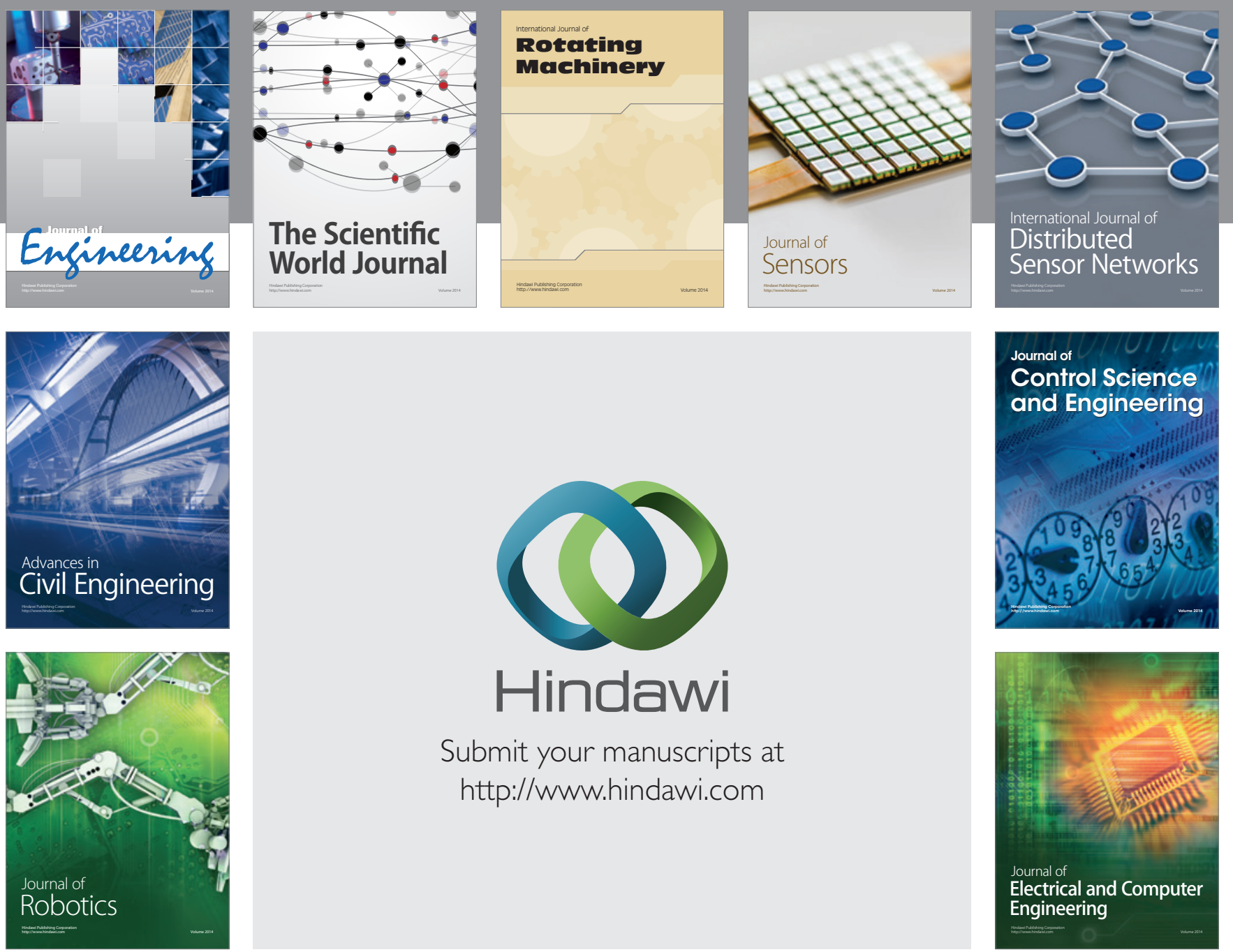

Submit your manuscripts at

http://www.hindawi.com
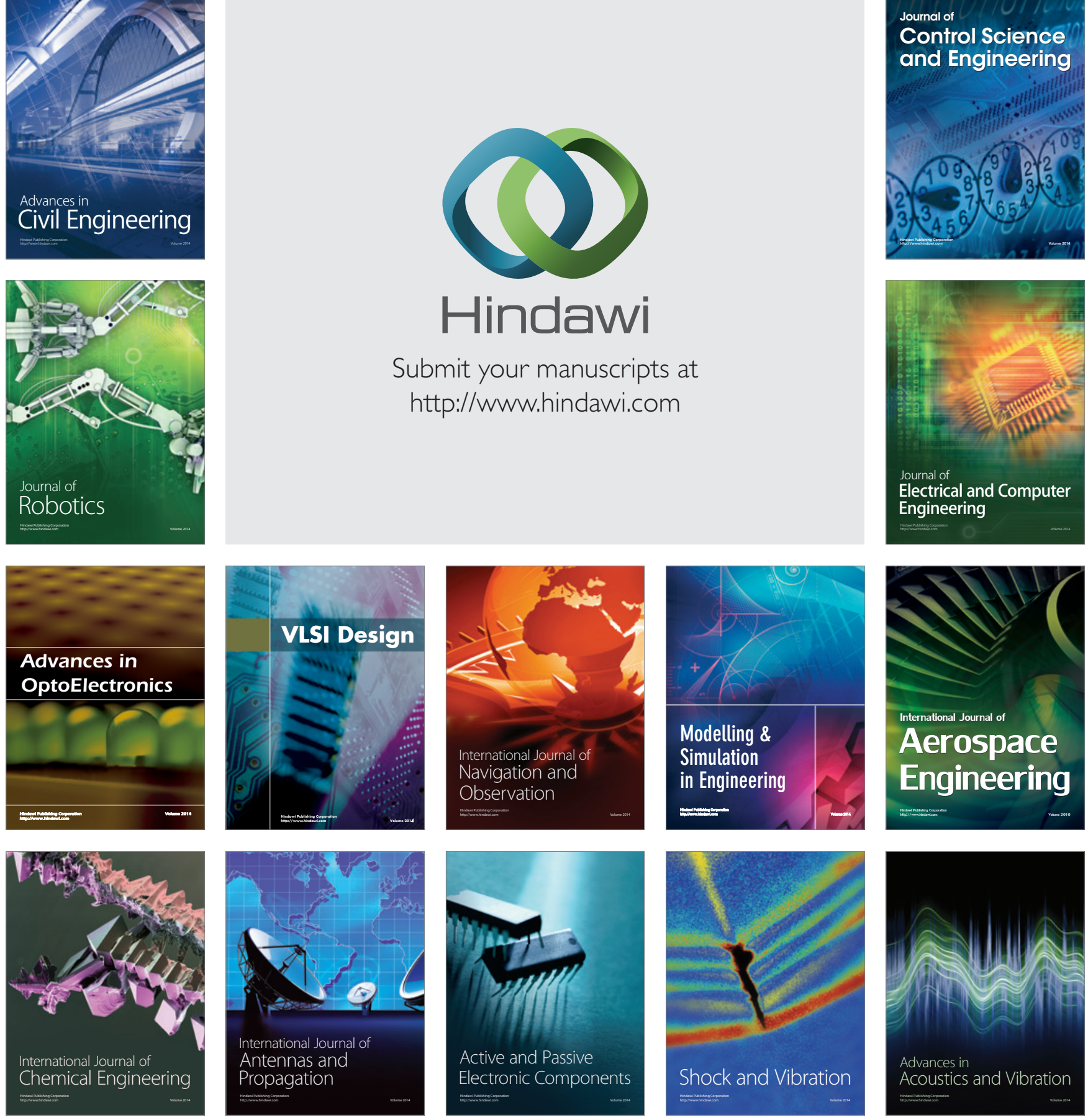